\title{
Mönckeberg's Arteriosclerosis
}

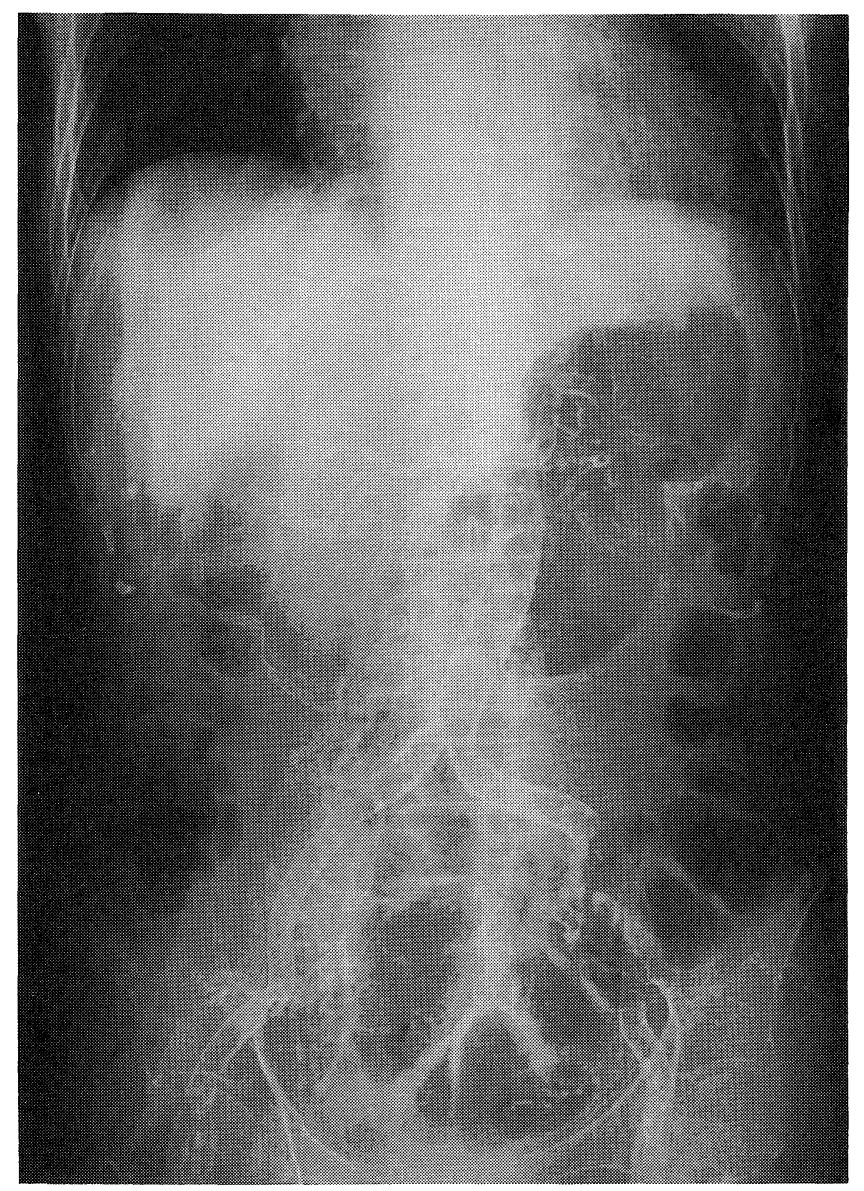

Figure. Abdominal plain X-ray film showed diffuse calcification of the abdominal aorta and its major branches.

Mönckeberg's arteriosclerosis is a rare form of arteriosclerosis, and is distinct from atherosclerosis. Mönckeberg's arteriosclerosis is characterized by medial calcinosis of the arteries of the lower extremities, and in most cases develops in patients with type 2 diabetes mellitus.

A 70-year-old woman with a history of type 2 diabetes mellitus for over 30 years and hemodialysis for 20 years was admitted to our hospital because of serious gangrene of the left foot. Abdominal plain X-ray film on admission showed diffuse calcification of the abdominal aorta and its major branches, ie, celiac artery, superior and inferior mesenteric arteries, bilateral atrophic renal arteries and bilateral iliac arteries (Figure). Diabetic gangrene was diagnosed, and the left leg below the knee was amputated surgically. The tibial artery obtained from the amputated left leg showed massive calcification and ossification of the media, so-called Mönckeberg's arteriosclerosis, and severe thickening of the intima, so-called atherosclerosis.

Key words: atherosclerosis, diabetes mellitus 
Tsutomu AraKI

The Department of Internal Medicine, Saiseikai Kanazawa Hospital Received for publication November 13, 2001; Accepted for publication November 28, 2001 Reprint requests should be addressed to Dr. Tsutomu Araki, the Department of Internal Medicine, Saiseikai Kanazawa Hospital, Ni 13-6, Akatsuchi-machi, Kanazawa, Ishikawa 920-0353 